\title{
Shorelines Extraction and Generalization Using Spatiotemporal Datasets
}

\author{
Ahmed F. Elaksher \\ Civil Engineering Department, Cal Poly Pomona University, Pomona, CA 91768, USA \\ Email: afelaksher@cpp.edu
}

\begin{abstract}
This paper discusses integrating multiple remotely sensed measurements, spatiotemporal databases, coastal hydrological modeling, and geospatial information analysis to study the impact of water level changes on the shoreline geometry in order to support coastal geospatial information systems and decision making. Different shorelines are generated using a CTM and a WSM. The CTM is generated using multiple remotely sensed datasets and spatiotemporal databases, while the WSM is provided using a coastal hydrological model. Two shoreline generalization schemes are implemented to simplify the shoreline geometry. Experiments for estimating the shoreline geometry at different water levels were performed using each generalization scheme. The relationship between the shoreline geometry and the water levels was studied. High correlation between water level changes and the changes in the shoreline geometry was observed. The proposed algorithm can be used in creating or updating coastal geospatial databases, managing the dynamic natural of shorelines, and making scientific decisions in coastal environments.
\end{abstract}

Keywords: Bathymetry, DEM, extraction, generalization, statistics.

\section{Introduction}

Shorelines are recognized as unique features on Earth. They are one of 27 global "geo-indicators" referred to by the International Union of Geological Science [1]. Despite their complexity, shorelines are widely used by the coastal and marine community. Shorelines are required to produce nautical charts, to define legal boundaries, and to derive offshore territorial limits. In addition, shorelines are crucial for many coastal applications including coastal development, coastal environmental protection, and coastal resource management and decision-making.

Shorelines have never been stable in terms of their long-term and short-term positions. Shoreline changes are usually caused either by natural processes or human activities. The natural processes may be phenomena such as waves, wind, currents, storms and erosion. The human activities affecting the shorelines are, for example, land reclamation, recreation beaches, land-use of the coastal zones, and structures built along the shorelines. In a Geographic Information System (GIS) it is so far impossible to depict the dynamic characteristics of the shoreline. In practice, instantaneous shorelines cannot be directly used for shoreline mapping and navigation, nor can they be employed for quantifying shoreline changes. A shoreline that is defined based on a stable vertical datum can be treated as a reference shoreline and used to differentiate shoreline changes. Such a shoreline is called a tide-coordinated shoreline that is the linear intersection between the coastal land and a desired water level.

The National Ocean Service (NOS) is responsible for the delineation of accurate tide-coordinated shorelines. These shorelines are defined when the water level coincides with either one of two standard tidal datum: Mean High Water (MHW) or Mean Lower Low Water (MLLW). The delineation process is accomplished by aerial photogrammetric surveys of the coast that are tide coordinated, i.e., timed to coincide closely with the time of MHW or MLLW. This process is expensive and needs special logistics and complicated processing procedures.

Conventionally, shoreline mapping is carried out using filed surveying methods, such as plane tables, alidades, theodolites, and electronic positioning methods. In addition, current and historical aerial photographs have been used widely in shoreline mapping and change detection [2]. Since the late 1930's, National Geodetic Science (NGS) has been using georeferenced, high-resolution aerial photographs for 
monitoring shoreline recession rates, beach changes, bluff tipping over, and relevant coastal changes [3]. Aerial images were used in [4] and [5] for analyzing shoreline positional changes. Satellite-imaging systems have also been utilized for monitoring coastal dynamics [6], [7], and [8]. In addition, other studies have integrated both historical aerial photographs and recent satellite imagery in assessing changes in areas neighbouring water bodies [9].

Active remote sensing sensors, including light detection and ranging (LIDAR) and synthetic aperture radar (SAR), have also been investigated and evaluated. For example, LIght Detection And Ranging (LIDAR) datasets have been employed in shoreline mapping and change detection activities [10] and [11]. Other remote sensing technologies, such as Synthetic Aperture Radar (SAR), have also been used for similar applications [12]. Integrating active and optical remote sensing datasets provides reliable and automatic solutions for coastal mapping and change detection, [13] and [14].

Changes in water levels have vital impact on shoreline geometry [15] and [16]. As water level rises, the shoreline responds by flooding or eroding. This can result in loss of land, increased vulnerability to flooding, accelerated erosion along the shore, and habitat loss. The water level of Lake Erie, for example, is continuously exhibiting natural fluctuation including: long-term, seasonal, and daily changes as a result of the complex interaction between climate, wind, precipitation, bathymetry, and water surface [17]. For Lake Erie, a wide range of recorded lake levels $(6.2 \mathrm{ft})$, with a maximum of $574.3 \mathrm{ft}$ in June 1986 and a minimum of $568.1 \mathrm{ft}$ in February 1936 has been observed [18]. The lake is a very dynamic waterbody and the shoreline is eroding by less than 1 meter per year [19].

In this paper, the impact of water level changes on the shoreline geometry is investigated. First, shorelines are generated as the intersecting line between Coastal Terrain Models (CTM) and Water Surface Models (WSM). CTM are generated by combining Digital Terrain Models (DTM) that represents land topography and waterbed topography represented by bathymetry. Water surface models are estimated from a hydrological modeling system. Two shoreline generalization schemes are then examined using mathematical polynomial using fixed length and variable length generalization schemes. The evaluation of the results of both generalization schemes demonstrated that the variable length generalization scheme results are stable. This endorsed the use of the second scheme in this research. Experiments for estimating the shoreline polynomial coefficients at different water levels were then performed. Different shorelines were generated at different water levels. Then the shoreline polynomial coefficients were computed and the relationship between the polynomial coefficients and the water levels was examined. The results using different mathematical polynomials showed that the zero order polynomial coefficients are highly correlated with the water level changes.

\section{Generating Shorelines Using CTM and WSM}

A shoreline is a linear intersection of the water surface and the coastal land. In this research, coastal land is represented by the CTM and water surface is represented by the WSM. In this section the generation of the CTM and the WSM will be presented.

\section{$2.1 \quad$ CTM Generation}

The CTM contains the topographic information in a narrow zone of the coast and near-shore bathymetry. They are generated by combining the DTM representing land topography and the waterbed topography represented by bathymetry data. As figure 1 shows, the study area for coastline change analysis extends along the south shore of Lake Erie. The DEM was generated from National Elevation Dataset (NED) products, figure 1. NED is the United States Geological Survey (USGS) main source for topographic datasets. NED stores DEMs as a seamless raster elevation dataset for the U.S. at one arc-second (approximately 30 meters) grid spacing. These topographic data are collected mainly from USGS map-based DEM that have a resolution of either 10 meters or 30 meters. Bathymetry data was provided by the National Geophysical Data Center (NGDC) in the National Oceanic and Atmospheric Administration (NOAA), figure 2 [20]. The data has been compiled with a one-meter contour interval with scales ranging between 1:100,000 and 1:2,500. The bathymetry was generated from digital sounding data combined with archived sounding data. Trackline separations range from about $125 \mathrm{~m}$ to $500 \mathrm{~m}$ for nearshore areas and $500 \mathrm{~m}$ to $2500 \mathrm{~m}$ for the open lake regions. 


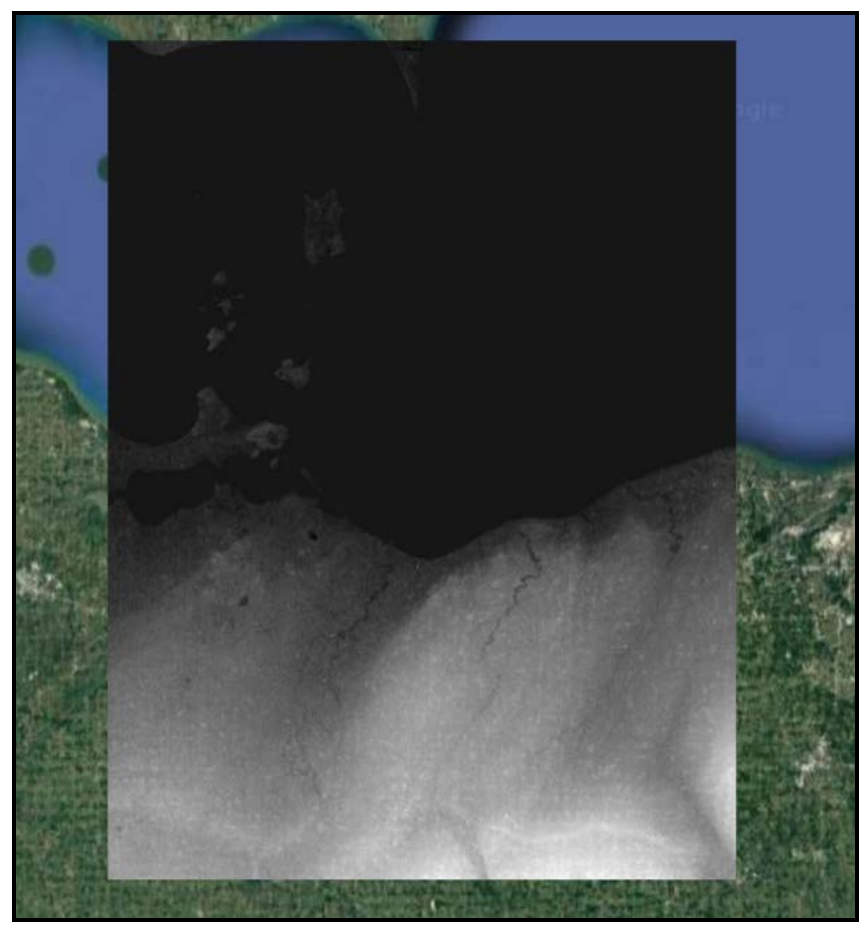

Figure 1. DTM for the study area.

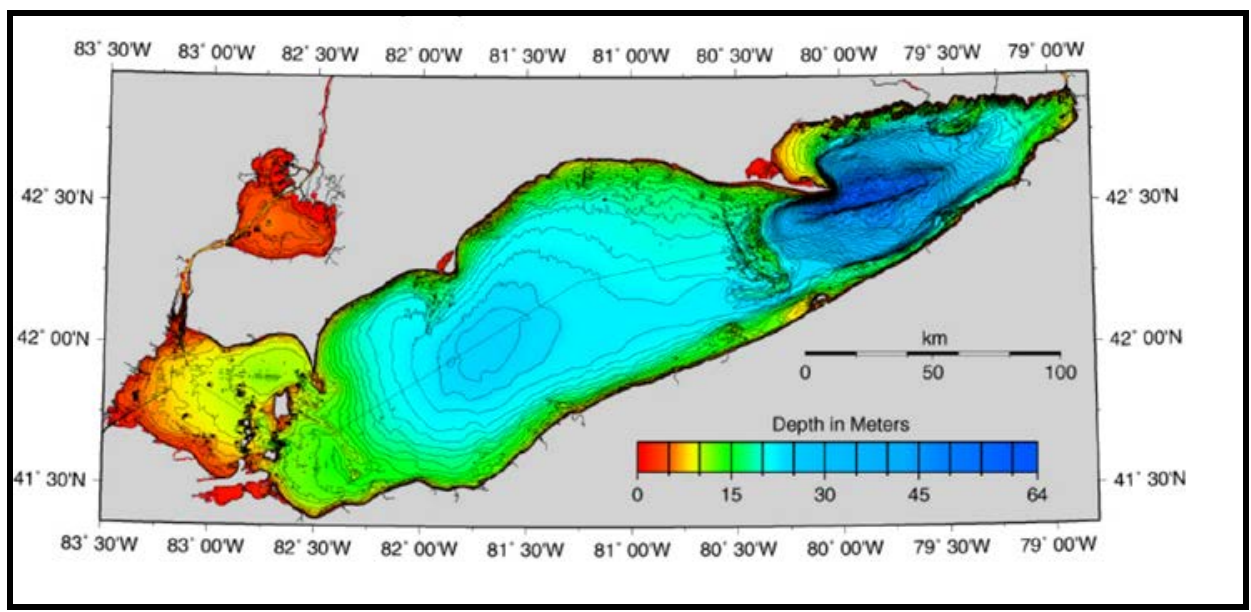

Figure 2. Lake Erie bathymetry data.

Since both datasets are available from different sources, collected at different times with different specifications, they need to be registered horizontally and vertically. ArcGIS was used to register both datasets horizontally in the North American Datum of 1983 (NAD 83). In addition, the North American Vertical Datum of 1988 (NAVD 88) was selected as the vertical datum. Elevations conversion was implemented through VDatum. Water penetrating LIDAR bathymetric survey with the U.S. Army Corps of Engineers SHOALS (Scanning Hydrographic Operational Airborne LIDAR Survey) are utilized in these gaps. 


\subsection{Water Surface Generation}

The Water Surface Model (WSM) is created from tide gauge measurements surrounding Lake Erie. In the USA, there are eight gauge stations along the perimeter of Lake Erie that provide hourly water levels. The data of these stations is published by Center for Operational Oceanographic Products and Services (CO-OPS). In addition, there are seven stations on the Canidian side of the lake and they are managed by the Marine Environmental Data Service (MEDS). Spatial distribution of the stations is exhibited in figure 3. Kriging interpolation was utilized in generating water surfaces for the lake. This interpolation method estimates values modeled through a Gaussian process governed by prior covariances. It outputs the optimal linear unbiased prediction of the interpolated values under suitable assumptions on the priors [21]. Computed elevations are referenced to the International Great Lakes Datum of 1985 (IGLD 85). A hydraulic corrector needs to be applied to convert them to the NAVD 88 dynamic heights. The dynamic heights are then transferred to conventional orthometric heights through equation $1[22]$.

$$
H=\frac{H_{d y m} \cdot \gamma_{0}}{g \cdot 0.0424 H}
$$

where $\mathrm{H}$ is the orthometric height, $\mathrm{H}_{\text {dym }}$ is the dynamic height, $g$ is the gravity measured at a ground point and $\gamma_{0}$ is normal gravity.

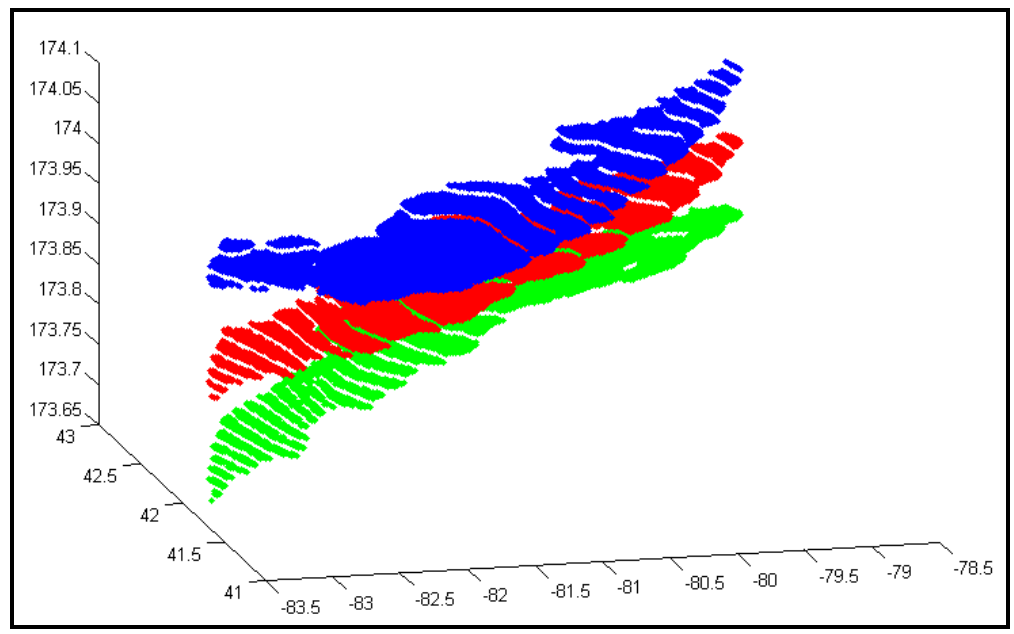

Figure 3. Three interpolated water surfaces at different times.

\subsection{Extracting Shorelines from CTM and WSM}

Theoretically, a shoreline is derived by subtracting the WSM from the CTM. Those cells with differential value of zero represent the shoreline, figure 4. However, several challenges need to be carefully watched for and solved to obtain a high quality shoreline. Firstly, the subtraction result of the CTM and WSM needs to be smoothed so that the shorelines are continuous lines. We convolved the grid with a 2-D Gaussian smoothing operator to remove any noise. In addition, shoreline segments whose lengths are smaller than a predefined threshold are eliminated. Furthermore, a classification based on the elevation/bathymetry differential values is performed to delineate grid points into land, water, and land-water interaction points and to create a thematic image. Subsequently, a clump operation groups the same kinds of grid points together to form clumps of land, water, and land-water interaction areas. After a noise detection and deletion process, the refined clump image is used to find the shoreline which is defined as one of the boundaries of the clump areas. In shoreline detection, topological information indicating that a shoreline separates water from land is also checked. The raster or grid shoreline is then converted to the vector shoreline. Finally, after a visual inspection and editing process, the digital shoreline becomes available for various applications. More details could be found in [23]. 


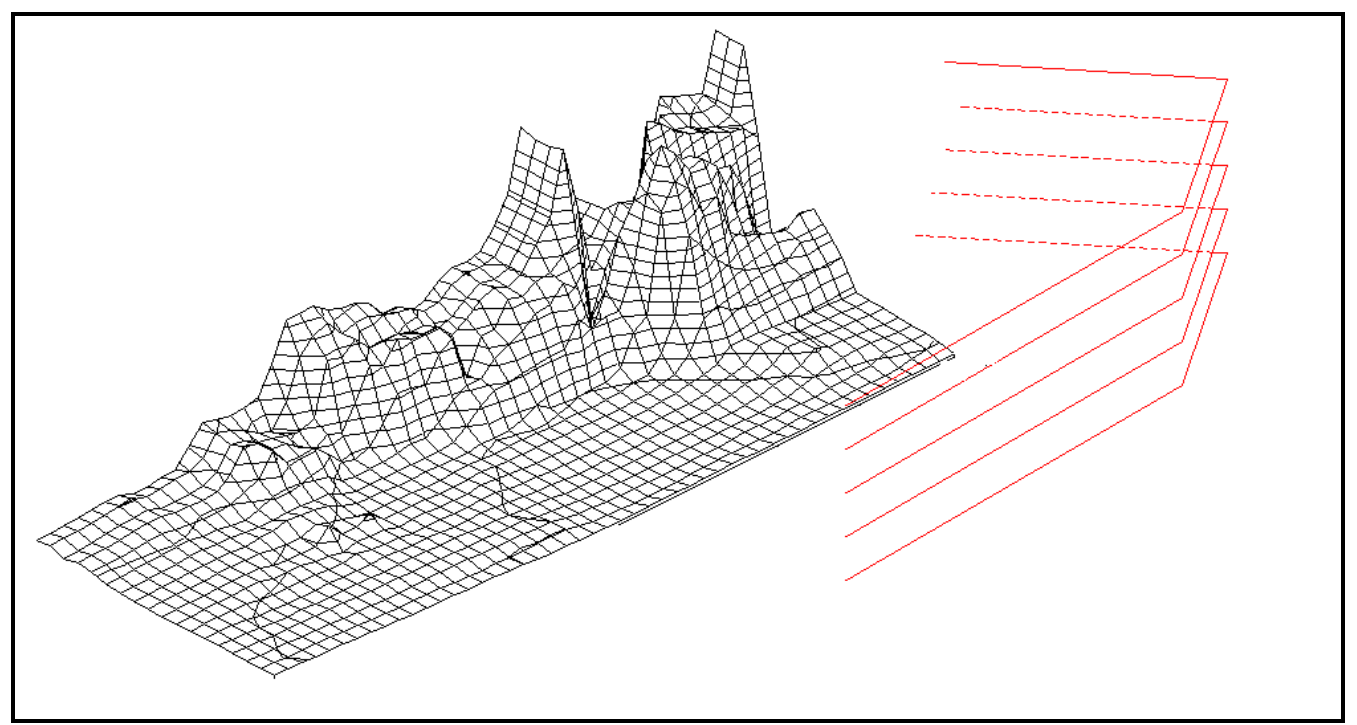

Figure 4. CTM and water surface intersection.

\section{$3 \quad$ Validation of Shoreline Generalization Using Mathematical Polynomial}

The 3D positions of the shoreline can be described, depending on the length and complexity of the shoreline, by a 3D complex line. In principle, the horizontal position of the shoreline can be presented using equation (2).

$$
\begin{aligned}
& x=F_{x}(\Omega, \Phi) \\
& y=F_{y}(\Omega, \Phi)
\end{aligned}
$$

Equation (2) states that, $\mathrm{x}$ and $\mathrm{y}$ are functions of the coastland geometry $\Omega$ and water surface $\Phi$ and it can be rewritten and simplified as $(y=F(x))$. The function $F(x)$ can be represented by piecewise polynomials. In this research $1^{\text {st }}$ and $2^{\text {nd }}$ order polynomials will be used to represent the shoreline. A polynomial is an algebraic expression with one term receiving most of the attention in shape description. Generally, shapes are represented by parametric form and cannot be represented with one-value functions. Therefore, two-dimensional shapes are represented by sets of parameters for each coordinate of a point location $(\mathrm{x}, \mathrm{y})$. In this study, the shoreline will be divided into polynomial-pieces with either fixed length or variable lengths. The final objective is to verify that any shoreline can be represented using polynomials regardless of the shoreline shape. Two schemes are designed and implemented for this investigation. The Root Mean Square Error (RMS) for each scheme will be used to either validate or invalidate the generalization scheme. Five shorelines will be generated by intersecting five WSM at five randomly selected water levels and a coastal terrain model for the research area, figure 5. Each shoreline will be represented by a number of points with a sampling rate of 30 meters that corresponds to the coastal terrain model pixel size.

A lest squares adjustment model, equation 3, is used with each scheme to compute the residuals. The horizontal $(x$ and $y$ ) coordinates of the shorelines points will be used as observations. The polynomial coefficients will be used as the unknowns in the model. As output, the least squares model will produce the residual for each scheme. The residuals will then be used to compute the RMS for each scheme.

$$
\begin{aligned}
& \mathrm{Av}+\mathrm{B} \Delta \mathbf{f}= \\
& \left.\Delta \mathrm{B}=\mathbb{B}{ }^{t} \mathbf{f}\right) \bullet
\end{aligned}
$$

where $\mathbf{A}$ is the coefficient matrix of the observations, $\mathbf{v}$ is the residual vector for the observations, $\mathbf{B}$ is the coefficient matrix of the unknown parameters, $\Delta$ is the vector of unknown parameters, and $\mathbf{f}$ is the coefficient vector of the observation equations. 


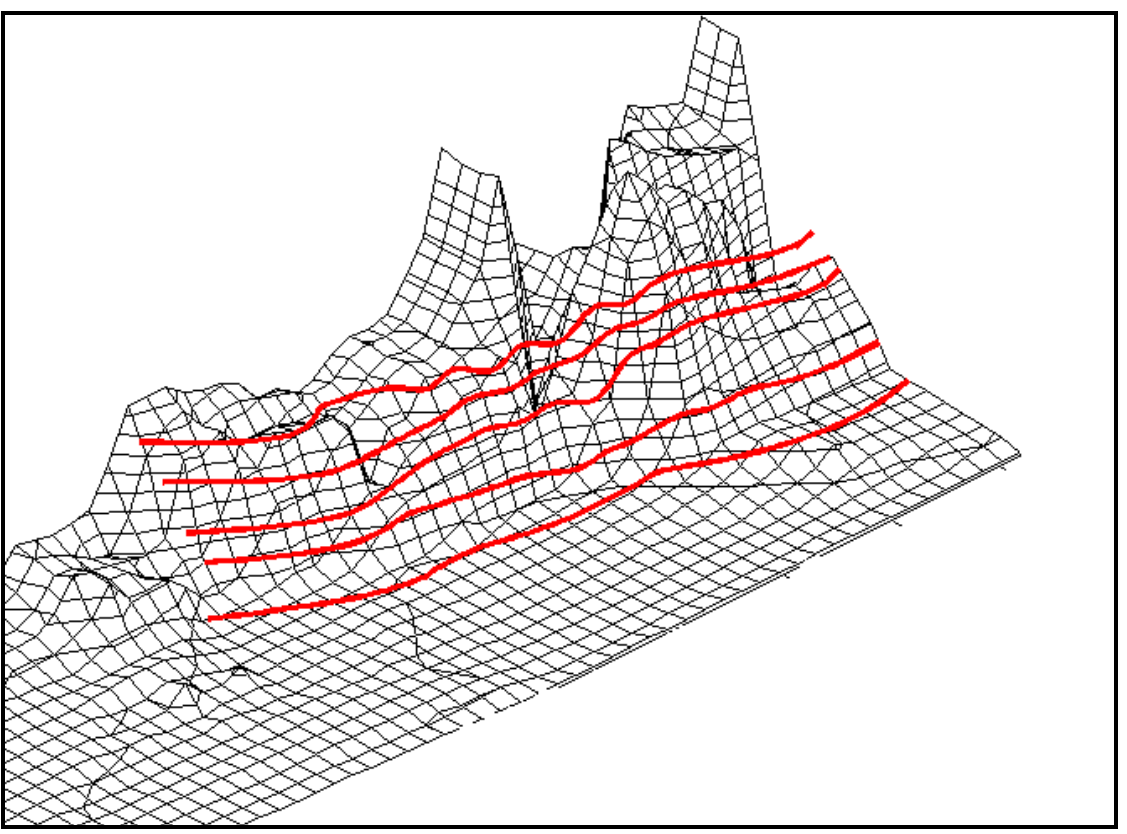

Figure 5. The CTM and the intersecting shorelines.

\subsection{Shoreline Generalization Using Fixed Length Spans}

The fixed length generalization of the shoreline was implemented using different spans $(50,100,200,500$, and 1000 points). For each polynomial the residuals were computed. In order to conclude whether this generalization scheme is valid, it is tested using the following hypotheses:

$$
\begin{array}{ll}
H_{o}: \mu=\mu_{o} & H_{1}: \mu \neq \mu_{o} \\
\text { and } & \\
H_{o}: \sigma=\sigma_{o} & H_{1}: \sigma>\sigma_{o}
\end{array}
$$

For this test $\mu_{o}=0.0$ meter and $\sigma_{o}= \pm 15$ meters (these values are calculated based on the horizontal accuracy of the DTM derived by USGS) and at the level of significance $(\alpha)$ is $95 \%$. The results of the two tests for each shoreline span are shown in table 1 , where $\bar{x}$ represents the sample mean and $s$ represents the sample standard deviation. Table 1 shows that the results of testing the variance are not stable and are based on the shoreline span. The results show that for short shorelines, the test is accepted while for long shorelines the test is rejected. The results also suggest the use of short shoreline spans. However, these spans can't be determinant and needs an extensive investigation and analysis for the shoreline to decide optimal shoreline spans. In addition, for some cases false spans might be generated in areas such as harbors. The same trend was observed for the case of $2^{\text {nd }}$ order polynomial, table 2.

Table 1. Results for $1^{\text {st }}$ order shoreline generalization using fixed length spans

\begin{tabular}{ccccc}
\hline Shoreline Span & $\bar{x}$ & $\boldsymbol{S}$ & Test of Mean & Test of Variance \\
\hline 50 & 0 & 2 & Accepted & Accepted \\
100 & 0 & 3 & Accepted & Accepted \\
200 & 0 & 3 & Accepted & Accepted \\
500 & 0 & 32 & Accepted & Rejected \\
1000 & 0 & 62 & Accepted & Rejected \\
\hline
\end{tabular}


Table 2. Results for $2^{\text {nd }}$ order shoreline generalization using fixed length spans

\begin{tabular}{ccccc}
\hline Shoreline Span & $\bar{x}$ & $\boldsymbol{S}$ & Test of Mean & Test of Variance \\
\hline 50 & 0 & 1 & Accepted & Accepted \\
100 & 0 & 2 & Accepted & Accepted \\
200 & 0 & 4 & Accepted & Rejected \\
500 & 0 & 14 & Accepted & Rejected \\
1000 & 0 & 32 & Accepted & Rejected \\
\hline
\end{tabular}

\subsection{Shoreline Generalization Using Variable Length Spans}

In order to overcome the deficiency of the fixed length shoreline generalization scheme, a variable length shoreline generalization scheme is implemented in this research. The scheme starts by having the first span of length $(n+1)$ where $(n)$ is the polynomial order, i.e. $(n+1)$ points. Then a polynomial is fitted to these points. If a statistic representing the fitting residuals is smaller than a preselected threshold, the next point of the shoreline is added to the span and the statistic is recalculated. Points are added sequentially until the statistic gets larger than the threshold. In this case, the last point is not accepted and a new span starts. The process is recursively carried out until the entire shoreline is divided. The statistic used in this research is the RMS. The process is shown in figure 6 . The results of examining a number of different thresholds are presented in table 3. The table shows that as the threshold increases the number of spans decreases. The process grantees that the maximum RMS is less than the preselected threshold. The threshold is selected based on the shoreline topography, the quality of the mapped shoreline, and the characteristics of the coastal area.

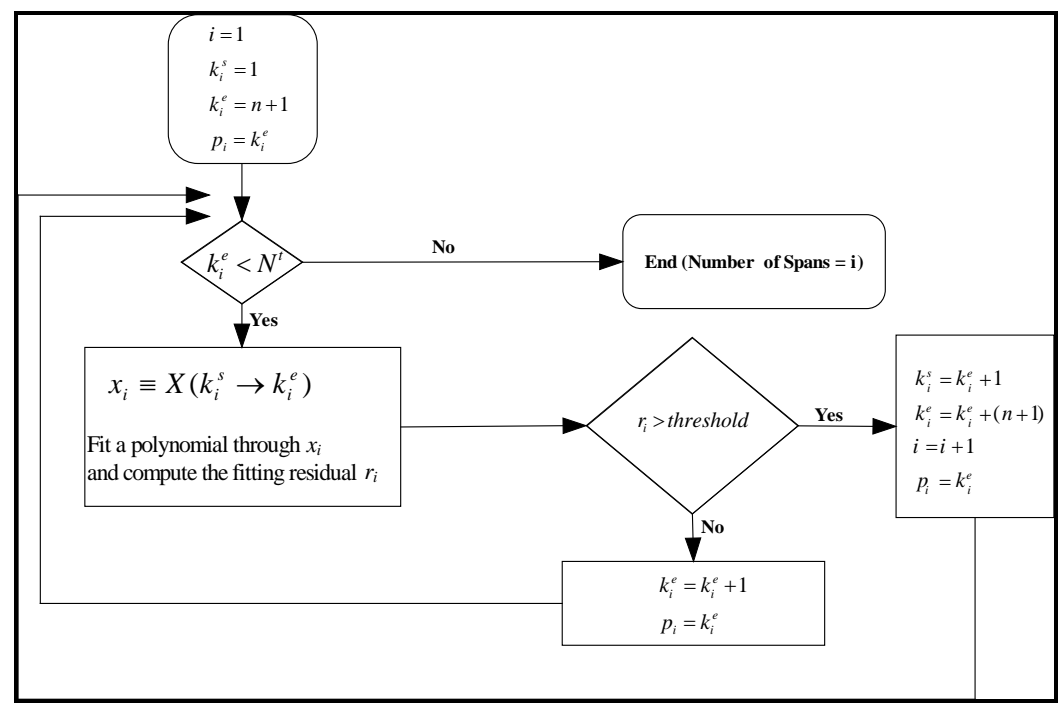

Figure 6. Shoreline generalization using variable length spans.

Table 3. Results for $1^{\text {st }}$ order shoreline generalization using variable length spans

\begin{tabular}{ccc}
\hline Threshold & Maximum RMS & Number of spans \\
\hline 5 & 4.9 & 58 \\
15 & 14.9 & 27 \\
30 & 29.9 & 18 \\
\hline
\end{tabular}




\section{Impact of Water Level Changes on Changes in Shoreline Geometry}

\subsection{Theoretical Analysis}

In order to justify the research concept, a theoretical investigation using the extracted shorelines is conducted. The process consists of three main steps. First, the water level over a long period is modeled. In the second step, polynomials are used to simulate the shoreline. For each polynomial, a parameterization scheme is implemented. In this process, the points contributing to the shoreline are used in a least square adjustment model to find the parameters representing the shoreline. In the last step, the effect of changing the water levels on the parameters that represent the shoreline geometry is analyzed.

\subsection{Water Level Generation}

The water heights are assumed to change on the long-term and short-term scales. At a given time (t), the water level can be computed using equation 4 .

$$
h(t)=F^{l}(t)+F^{s}(t)
$$

where $F^{l}(t)$ is a function that represents the long term water level changes, $F^{s}(t)$ a function that represents the short-term water level changes.

A number of linear, curved, sinusoidal, and discontinuous functions are used to represent both $F^{l}(t)$ and $F^{s}(t)$. For example, figure 7 shows a case of five-year change with a sudden change in water level after two years. The case is modeled through:

$$
\begin{aligned}
& F^{l}(t)= \begin{cases}a t+b & 0 \leq t \leq 365 \times 2 \\
c t+d & 365 \times 2 \leq t \leq 365 \times 5\end{cases} \\
& F^{s}(t)=e \sin (f t+g) \quad 0 \leq t \leq 365 \times 5
\end{aligned}
$$

where $a, b, c, d, e, f, g$ are constants and $\mathrm{t}$ is measured in days.

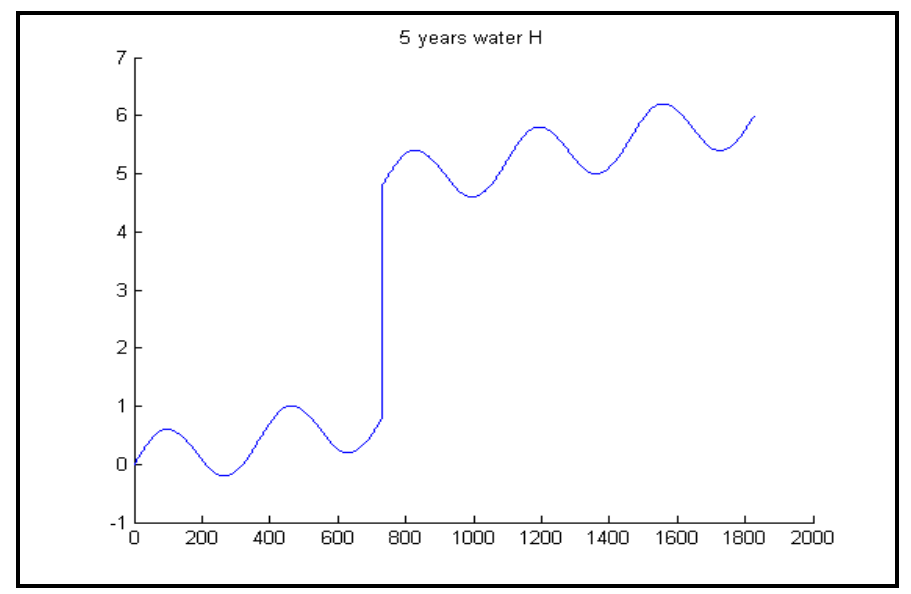

Figure 7. Changes of water level over five years.

\subsection{Shorelines Generation}

In order to generate shorelines, simple geometry is used to represent the intersection between the water surface and the coastal land as shown in figure 8. The figure shows that a change $(\Delta h)$ in water level will generate a change $(\Delta p)$ in the shoreline position. The relation between $(\Delta h)$ and $(\Delta p)$ can be computed using the form $\left(\Delta p=\Delta h^{*} s\right)$, where $s$ represents the coastland slope. For this test $s$ is selected to be $1 / 100$. Moreover, two shoreline mathematical models are used to represent the horizontal location 
of the shoreline: the $1^{\text {st }}$ order polynomial model $\left(y=a_{1} x+a_{0}\right)$ and the $2^{\text {nd }}$ order polynomial model $\left(y=a_{2} x^{2}+a_{1} x+a_{0}\right)$.

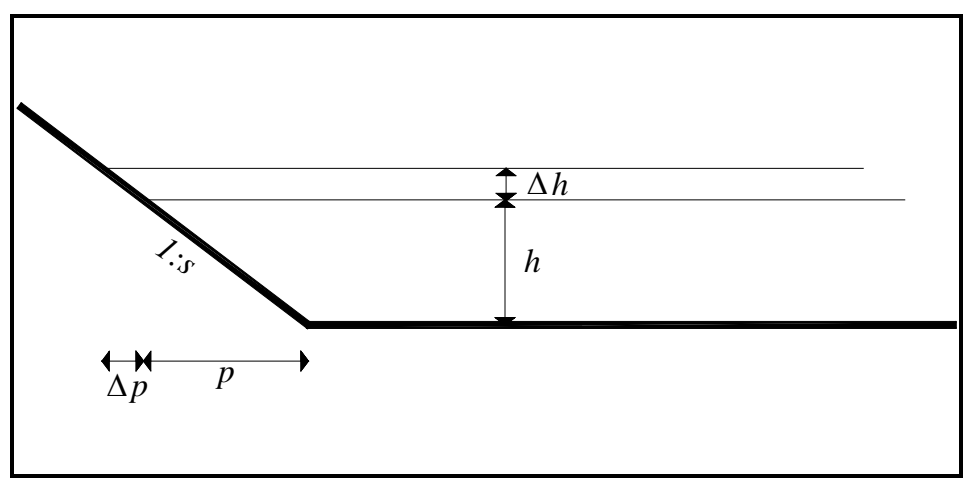

Figure 8. Intersecting water level and coastal land.

\subsection{Effect of Water Level Changes on Shoreline Geometry}

The following scheme is used to investigate the effect of water level changes on the geometry of the shorelines. Let $\left(y_{1}=a_{1}{ }^{1} x+a_{0}{ }^{1}\right)$ represent the shoreline geometry at water level $\left(h_{1}\right)$ and $\left(y_{2}=a_{1}{ }^{2} x+a_{0}{ }^{2}\right)$ represent the shoreline geometry at water level $\left(h_{2}\right)$. The relationship between $\left(h_{2}\right)$ and $\left(h_{1}\right)$ is described as $\left(h_{2}=h_{1}+\Delta h\right)$. The effect of the water level change $(\Delta h)$ on the shoreline geometry is represented by $(\Delta p)$. In this study, shorelines are assumed to be parallel, therefore $\left(a_{0}{ }^{2}=a_{0}{ }^{1}+\Delta p\right)$ and $\left(a_{1}{ }^{2}=a_{1}{ }^{1}\right)$. This indicates that the changes in the parameter $a_{0}$ are linearly correlated to the changes in water level. In addition, water level changes don't affect the parameters $a_{1}$ and $a_{2}$. This was verified by examining the shorelines generated at each water level and investigating the relationship between the shorelines parameters and the water level changes

\subsection{Relationship between Water Level Changes and Changes in Shoreline Geometry}

This section presents the analyses and modeling of the shoreline geometry changes as a respond to the water level rise or drop. Five shorelines are used and the statistic for each shoreline is computed. The maximum statistic is compared against the preselected threshold. If the maximum statistic is smaller than the threshold the next point of in each shoreline is added to each shoreline span and the statistics are recalculated. Points are added sequentially to each shoreline until the maximum statistic for each shoreline gets larger than the threshold. In this case, the last point in each shoreline is not accepted and new spans from the last point for each shoreline start. The process is recursively carried out until all shorelines are divided. The modified scheme provides sets of correspondence spans in all shorelines. In addition, it grantees that the maximum statistic is less than the preselected threshold. Figure 9 shows the generated spans for each shoreline using a $2^{\text {nd }}$ order polynomial. For each span, the correlation coefficients between the polynomial coefficients and the water levels are computed. The maximum and minimum correlation coefficients are shown in table 4 for both $1^{\text {st }}$ and $2^{\text {nd }}$ order polynomial fittings.

Table 4. Correlation between water level changes and shoreline geometry

\begin{tabular}{cccccc}
\hline & \multicolumn{1}{c}{$1^{\text {st }}$ Order Polynomial } & \multicolumn{3}{c}{$2^{\text {nd }}$ Order Polynomial } \\
\cline { 2 - 6 } & $\mathrm{a}_{0}$ & $\mathrm{a}_{1}$ & $\mathrm{a}_{0}$ & $\mathrm{a}_{1}$ & $\mathrm{a}_{2}$ \\
\hline $\begin{array}{c}\text { Max } \\
\text { Corr. Coff. } \\
\text { Min }\end{array}$ & 0.99 & 0.95 & 0.99 & 0.99 & 0.81 \\
$\begin{array}{c}\text { Corr. Coff. } \\
\text { Conyyyy}\end{array}$ & 0.94 & -0.62 & 0.94 & -0.66 & -0.88 \\
\hline
\end{tabular}




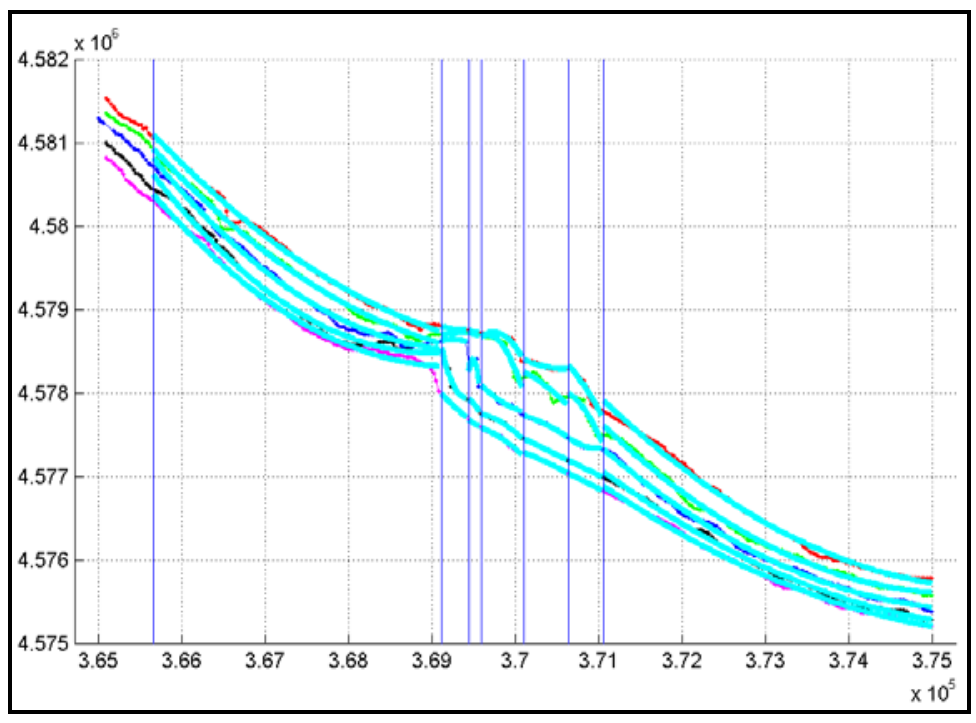

Figure 9. Generalized shorelines generated using variable length spans with a 30m threshold.

\section{$5 \quad$ Discussions and Conclusions}

In this paper, the impact of water level changes on shoreline geometry is investigated. First, shorelines are generating as the intersecting line between CTM and WSM. Then two shoreline generalization schemes are examined using mathematical polynomial to simplify the shoreline geometry using fixed length and variable length generalization schemes. The evaluation of the results of both generalization schemes demonstrated that the variable length generalization scheme results are stable. This supports the use of the second scheme in this research. Experiments for estimating the shoreline polynomial coefficients at certain water levels were then performed using both simulated and real data. Different shorelines were generated at different water levels. Then the shoreline polynomial coefficients were computed. Results using different mathematical polynomials showed that the zero order polynomial coefficients are highly correlated with the water level changes. Errors in the elevation model have a great impact on the proposed technique. In general, the elevation errors need to be smaller than the changes in water levels. Otherwise, there effect will superimpose the effect of the water level changes. A comprehensive analysis is needed to study the effect of all sources of errors in the system. This analysis should consider: the horizontal resolution of the elevation model, the accuracy of the estimated water level, the accuracy of the elevation model, and the accuracy of the extracted shoreline.

\section{References}

1. Lockwood, M., 1997. NSDI shoreline briefing to the FGDC coordination group, NOAA/NOS.

2. Thieler, E.R. and Danforth, W.W., 1994. Historical shoreline mapping (I): improving techniques and reducing positioning error. Coastal Research. 10(3), pp. 549-563.

3. Smith, G.L. and Zarillo, G.A., 1990. Calculating long-term shoreline recession rates using aerial photographic and beach profiling techniques. Coastal Research, 6(1), pp. 111-120.

4. Pradjoko, E., \& Tanaka, H. (2011). Aerial photograph of Sendai Coast for shoreline behavior analysis. Coastal Engineering Proceedings, 1(32), 92.

5. Sesli, F. A. (2010). Mapping and monitoring temporal changes for coastline and coastal area by using aerial data images and digital photogrammetry: A case study from Samsun, Turkey. International Journal of Physical Sciences, 5(10), 1567-1575.

6. García-Rubio, G., Huntley, D., \& Russell, P. (2015). Evaluating shoreline identification using optical satellite images. Marine Geology, 359, 96-105. 
7. Chen, W. W., \& Chang, H. K. (2009). Estimation of shoreline position and change from satellite images considering tidal variation. Estuarine, Coastal and Shelf Science, 84(1), 54-60.

8. Tarmizi, N. M., Samad, A. M., \& Yusop, M. S. M. (2014, March). Shoreline data extraction from QuickBird satellite image using semi-automatic technique. In Signal Processing \& its Applications (CSPA), 2014 IEEE 10th International Colloquium on (pp. 157-162). IEEE.

9. Sesli, F. A., Karsli, F., Colkesen, I., \& Akyol, N. (2009). Monitoring the changing position of coastlines using aerial and satellite image data: an example from the eastern coast of Trabzon, Turkey. Environmental Monitoring and Assessment, 153(1), 391-403.

10. White, S. A., Parrish, C. E., Calder, B. R., Pe'eri, S., \& Rzhanov, Y. (2011). Lidar-derived national shoreline: empirical and stochastic uncertainty analyses. Journal of Coastal Research, 62-74.

11. Brock, J. C., \& Purkis, S. J. (2009). The emerging role of lidar remote sensing in coastal research and resource management. Journal of Coastal Research, 1-5.

12. Bruno, M. F., Molfetta, M. G., Mossa, M., Nutricato, R., Morea, A., \& Chiaradia, M. T. (2016). Coastal observation through COSMO-SkyMed high-resolution SAR images. Journal of Coastal Research, 75(sp1), 795799.

13. Elaksher, A. F. (2008). Fusion of hyperspectral images and lidar-based dems for coastal mapping. Optics and Lasers in Engineering, 46(7), 493-498.

14. Kerfoot, W. C., Hobmeier, M. M., Yousef, F., Green, S. A., Regis, R., Brooks, C. N., \& Reif, M. (2014). Light detection and ranging (LiDAR) and multispectral scanner (MSS) studies examine coastal environments influenced by mining. ISPRS International Journal of Geo-Information, 3(1), 66-95.

15. Bilskie, M. V., Hagen, S. C., Medeiros, S. C., \& Passeri, D. L. (2014). Dynamics of sea level rise and coastal flooding on a changing landscape. Geophysical Research Letters, 41(3), 927-934.

16. Hajek, E., Paola, C., Petter, A., Alabbad, A., \& Kim, W. (2014). Amplification of shoreline response to sea-level change by back-tilted subsidence. Journal of Sedimentary Research, 84(6), 470-474.

17. Jones, D.M. (2009). Lake Erie Water Levels, online: http://geosurvey.ohiodnr.gov/lake-erie-geology/water-levels, last accessed: March 5th, 2017.

18. Wilcox, D. A., Thompson, T. A., Booth, R. K., \& Nicholas, J. R. (2007). Lake-level variability and water availability in the Great Lakes. US Geological Survey Circular 1311.

19. Highman, T. A. (1997). A Study of Soil Joints in Relation to Bluff Erosion Along Lake Erie Shoreline, Northeast Ohio. Kent, OH: Kent State University.

20. Holcombe, T. L., Taylor, L. A., Reid, D. F., Warren, J. S., Vincent, P. A., \& Herdendorf, C. E. (2003). Revised Lake Erie postglacial lake level history based on new detailed bathymetry. Journal of Great Lakes Research, 29(4), 681-704.

21. Cressie, N. A., 1993: Statistics for Spatial Data, Revised Edition, A Wiley-Interscience Publication, New York, 887 pp.

22. Heiskanen, W. A., and Moritz, H. (1967).Physical Geodesy. W. H. Freeman and Co., San Francisco, Calif

23. Li, R., Di, K., and Ma, R., 2002. Digital tide-coordinated shoreline. Marine Geodesy, (25), pp. 27-36. 